\title{
Functionalization and Hydrogenation of Carbon Chains Derived from CO
}

\author{
Maria Batuecas, Richard Y. Kong, Andrew J. P. White, Mark, R. Crimmin* \\ Department of Chemistry, MSRH, Imperial College London, 82 Wood Lane, Shepherds Bush, London, W12 0BZ, \\ UK.
}

ABSTRACT: Selective reactions that combine $\mathrm{H}_{2}, \mathrm{CO}$ and organic electrophiles (aldehyde, ketones, isocyanide) to form hydrogenated $\mathrm{C}_{3}$ and $\mathrm{C}_{4}$ carbon chains are reported. These reactions proceed by $\mathrm{CO}$ homologation mediated by $\left[\mathrm{W}(\mathrm{CO})_{6}\right]$ and an aluminum $(\mathrm{I})$ reductant, followed by functionalization and hydrogenation of the chain ends. A combination of kinetics (rates, KIEs) and DFT calculations has been used to gain insight into a key step which involves hydrogenation of a metallocarbene intermediate. These findings expand the extremely small scope of systems that combine $\mathrm{H}_{2}$ and $\mathrm{CO}$ to make welldefined products with complete control over chain length and functionality.

The controlled polymerization, hydrogenation and dehydration of $\mathrm{CO} / \mathrm{H}_{2}$ mixtures to form hydrocarbons by the Fischer-Tropsch (F-T) process is an essential reaction for industry. ${ }^{1,2}$ There has long been interest in controlling the selectivity of this reaction. ${ }^{3}$ Many have advocated the potential of homogeneous catalysts to lead to reaction products with defined molecular weight and oxygen content. 4,5

Despite these ambitions, homogeneous reactions that lead to F-T products are incredibly rare. ${ }^{4,6-10}$ Our fundamental understanding of this type of reactivity is limited; there are only a handful of well-defined systems that combine $\mathrm{CO}$ and $\mathrm{H}_{2}$ in a single reaction sequence to form either hydrocarbon $\left(\mathrm{C}_{\mathrm{x}} \mathrm{H}_{\mathrm{y}}\right)$ or oxygenate $\left(\mathrm{C}_{\mathrm{x}} \mathrm{H}_{\mathrm{y}} \mathrm{O}_{\mathrm{z}}\right)$ products. In 1991, Lippard and co-workers reported the reductive coupling and hydrogenation of $\mathrm{CO}$ to form cis-disiloxyethylene compounds, mediated by vanadium complexes. ${ }^{11}$ More recently, Peters and Suess reported a similar product from the hydrogenation of a CO derived iron dicarbyne. ${ }^{12} \mathrm{Hou}$ and co-workers have documented the hydrodeoxygenative cyclotetramerization of $\mathrm{CO}$ by a trinuclear titanium poly(hydride) complex to form a cyclobutanone product. ${ }^{13}$ Stephan and coworkers have shown that a simple lithium amide base $\left(\mathrm{LiNCy}_{2}\right)$ can react with $\mathrm{CO} / \mathrm{H}_{2}$ mixtures to form small amounts (<10\% yield) of an a-hydroxy amide derived from coupling and hydrogenation of two CO units. $^{14}$ 
These systems represent the limit of knowledge in this field and have clear limitations. To date only $\mathrm{C}_{2}$ and $\mathrm{C}_{4}$ hydrogenated chain-growth products have been isolated. There are no examples of generating more complex products by incorporating organic electrophiles (other than $\mathrm{CO}$ ) within the carbon chain. There is also a lack of detailed mechanistic information on the hydrogenation step. A broader scope and deeper understanding of these types of transformations could be an important factor in ultimately achieving selective F-T catalysis.

In this paper, we describe the direct hydrogenation of a series of $\mathrm{CO}$ homologation products, including for the first time, well-defined reactivity of $\mathrm{C}_{3}$ carbon chains. We show that F-T products can be obtained by reaction with $\mathrm{CO}$, organic electrophiles, a main group reductant and $\mathrm{H}_{2}$. We provide a mechanistic description of the key hydrogenation step, shedding light on a key $\mathrm{C}-\mathrm{H}$ bond formation pathway of relevance to F-T catalysis.

We have previously reported carbon-chain growth reactions from 1, [W(CO) $]$ and CO. ${ }^{15,16}$ Reaction of 2 with benzophenone at $100{ }^{\circ} \mathrm{C}$ in $\mathrm{C}_{6} \mathrm{D}_{6}$ led to the formation of $3 \mathrm{a}$ and $4 \mathrm{a}$ in $81 \%$ yield, in a $4: 1$ ratio based on ${ }^{1} \mathrm{H}$ NMR spectroscopy (Scheme 1).
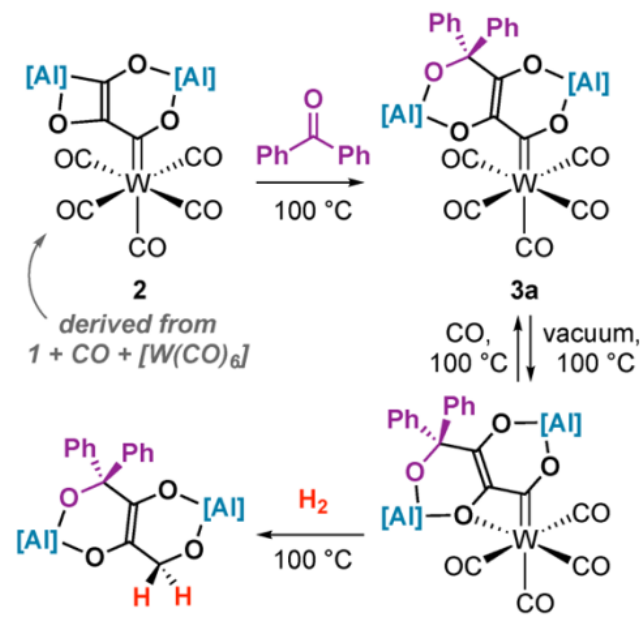

$5 a$

$4 a$

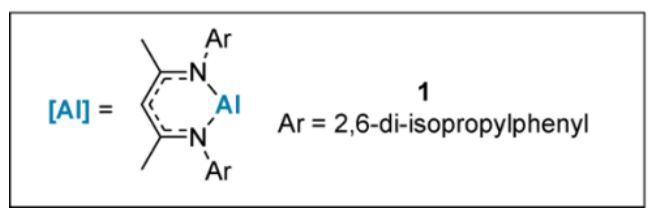

Scheme 1. Reactions of 2 with benzophenone and $\mathrm{H}_{2}$. 
The conversion of $\mathbf{3 a}$ to $\mathbf{4 a}$ is reversible. Heating mixtures of $\mathbf{3 a}+\mathbf{4 a}$ under $1 \mathbf{a t m}$. of $\mathrm{CO}$ for $12 \mathrm{~h}$ at $100{ }^{\circ} \mathrm{C}$ led to complete conversion to $\mathbf{3} \mathbf{a}$. Upon heating under vacuum, $\mathbf{3} \mathbf{a}$ partially converts back to $\mathbf{4 a}$. DFT calculations are consistent with the reversible reaction. Formation of $4 \mathbf{a}$ from $3 \mathbf{a}$ was calculated to be endergonic $\left(\Delta \mathrm{G}^{\circ}{ }_{298 \mathrm{~K}}=+6.2 \mathrm{kcal} \mathrm{mol}^{-1}\right)$ and occur via an interchange mechanism $\left(\Delta \mathrm{G}^{\ddagger}{ }_{298 \mathrm{~K}}=+25.4 \mathrm{kcal}\right.$ $\mathrm{mol}^{-1}$ ) (Figure 1a).

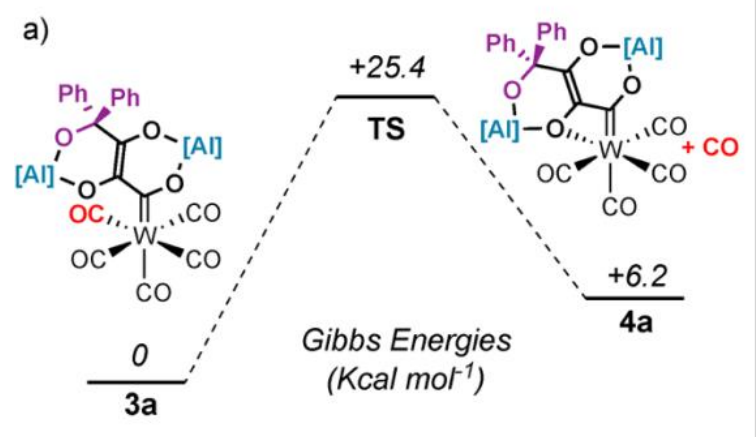

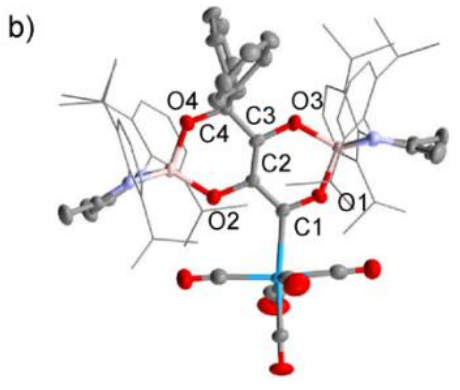

$3 a$

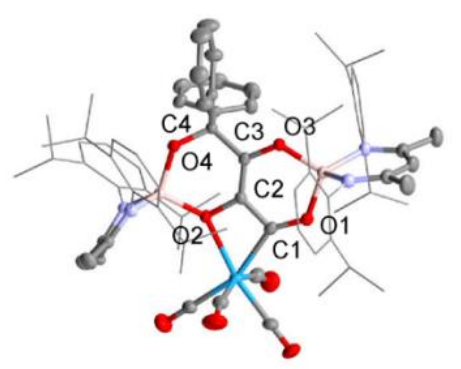

$4 a$

Figure 1: a). DFT calculated mechanism for transformation of $\mathbf{3 a}$ to $\mathbf{4 a}$. b). Solid state structures of $\mathbf{3 a}$ and $\mathbf{4 a}$.

Compounds $\mathbf{3 a}$ and $\mathbf{4 a}$ have been characterized by multinuclear NMR and IR spectroscopy. In $\mathrm{C}_{6} \mathrm{D}_{6}$ solution, $\mathbf{3 a}$ and $\mathbf{4 a}$ display ${ }^{13} \mathrm{C}$ NMR resonances for the metallocarbene ligand at $\delta=315.6$ and 310.9 ppm respectively. The equatorial and axial carbonyl ligands of $3 a$ are magnetically inequivalent and appear at $d=203.3$ and 205.1 ppm. For comparison, 4a shows three resonances for the CO ligands in the ${ }^{13} \mathrm{C}$ NMR spectrum at $\delta=215.5,218.8$ and $221.4 \mathrm{ppm}$ due to the reduction in symmetry. IR spectroscopy is consistent with a change in geometry around the metal center from $3 \mathbf{a}(v(C O)=2050$, 1897 and $\left.1871 \mathrm{~cm}^{-1}\right)$ to $4 \mathrm{a}\left(\mathrm{v}(\mathrm{CO})=1988,1874,1862\right.$ and $\left.1825 \mathrm{~cm}^{-1}\right)$ due to CO dissociation.

In the solid-state, the W-C bond length of 3a of 2.269(4) $\AA$ is longer than that of 2.195(3) $\AA$ found in 2. Formation of the $\mathrm{k}^{2}-\mathrm{C}, \mathrm{O}$ coordination mode occurs with a large distortion away from an ideal octahedral geometry at $\mathrm{W}$, an effect driven by the acute bite angle of $60.9(1)^{\circ}$ of the chelating ligand. ${ }^{17}$ This distortion also influences the geometry at the metallocarbene fragment. The $\mathrm{W}-\mathrm{C}^{1}-\mathrm{O}^{1}$ and $\mathrm{W}-\mathrm{C}^{1}-\mathrm{C}^{2}$ angles in $3 \mathbf{a}$ are $115.4(2)$ and $130.0(3)^{\circ}$, close to the expected value for a $\mathrm{sp}^{2}$-hybridised carbon center. Upon chelation to form $4 a$ these values become increasingly distorted away from an ideal geometry with the $\mathrm{W}-\mathrm{C}^{1}-\mathrm{O}^{1}$ angle expanding to $141.3(2)^{\circ}$ and $\mathrm{W}-\mathrm{C}^{1}-\mathrm{C}^{2}$ angle contracting to $99.4(2)^{\circ}$. 
Complex 4a reacts with $\mathrm{H}_{2}$. Treatment of a benzene solution of $4 \mathrm{a}$ with $\mathrm{H}_{2}$ (1 atm.) at $100{ }^{\circ} \mathrm{C}$ for $2 \mathrm{~h}$ led to the corresponding F-T type product $5 \mathrm{a}$ in $>95 \%$ NMR yield (Scheme 1). Attempts to crystallise this complex were unsuccessful, however compound 5a was characterised by diagnostic resonances at $\delta=$ $4.38 \mathrm{ppm}$ and $\delta=67.9 \mathrm{ppm}$, in the ${ }^{1} \mathrm{H}$ and ${ }^{13} \mathrm{C}$ NMR spectra respectively, assigned to the new methylene group formed upon $\mathrm{H}_{2}$ addition. Further analysis of the reaction mixtures revealed $\left[\mathrm{W}(\mathrm{CO})_{6}\right]$ and $\left[\mathrm{W}(\mathrm{CO})_{3}\left(\eta^{6}-\mathrm{C}_{6} \mathrm{D}_{6}\right)\right]$ as side products of hydrogenation. An isotope labelling experiment in which $\mathbf{4 a}$ was reacted with $D_{2}$ provided clear evidence for the formation of $5 a-D_{2}$ with the methylene group resonating at $d=4.38 \mathrm{ppm}$ in the ${ }^{2} \mathrm{H}$ NMR spectrum. Hydrogenation of $\mathbf{3 a}$ also directly leads to $\mathbf{5 a},{ }^{18}$ as does the reaction of $2, \mathrm{H}_{2}$ and benzophenone at $100{ }^{\circ} \mathrm{C}$.

The reaction scope was developed further (Table 1). A series of $\mathrm{C}_{4}$ homologation complexes (3b-e) were prepared from the reaction of 2 with $\mathrm{CO},{ }^{15} 3$-methylbenzaldehyde, 2-butanone, and 2,6-dimethylphenyl isocyanide. These reactions proceeded smoothly in all cases demonstrating that $\mathrm{C}_{3} \rightarrow \mathrm{C}_{4}$ chain growth is possible with a range of electrophiles. Hydrogenation of $\mathbf{3 b}$-e led to $\mathbf{5 b}$-e in $60-95 \%$ NMR yield. In the case of $3 \mathbf{e}$, the expected hydrogenation product can be observed spectroscopically but isomerizes to a more stable enamine tautomer under the reaction conditions. The reaction is not limited to $\mathrm{C}_{4}$ homologation products, as direct hydrogenation of 2 was also possible leading to the formation of the $\mathrm{C}_{3}$ analogue 5f. Remarkably, 5b could also be obtained in $50 \%$ NMR yield from a direct reaction of $\left[\mathrm{W}(\mathrm{CO})_{6}\right], 1$ and syngas ( $1: 1$ mixture of $\mathrm{H}_{2} / \mathrm{CO}, 1 \mathrm{~atm}$.) after 10 days at $100{ }^{\circ} \mathrm{C}$. While the reaction is slow, this experiment shows that there is an element of self-organisation in this system as F-T type products to be formed in a single step from simple starting materials. 

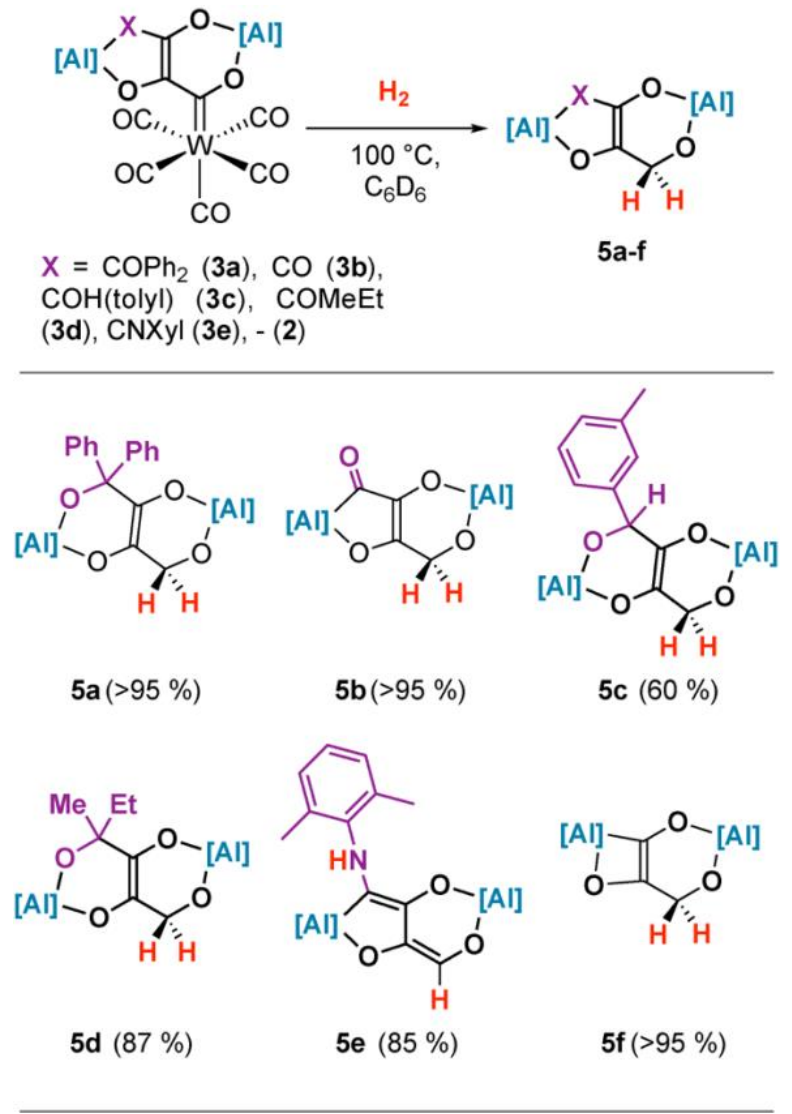

Table 1. Scope of hydrogenation reaction. Yield determined by ${ }^{1} \mathrm{H}$ NMR spectroscopy using 1,3,5trimethoxybenzene as external standard.

Further experiments and calculations were undertaken to gain insight into the key hydrogenation step. The reaction of $3 a$ with $\mathrm{H}_{2}\left(1 \mathrm{~atm}\right.$.) in benzene- $d_{6}$ at $100{ }^{\circ} \mathrm{C}$ was monitored as a function of time by in situ ${ }^{1} \mathrm{H}$ NMR spectroscopy. Kinetic data show that hydrogenation of $3 \mathbf{a}$ occurs as consecutive reactions with $\mathbf{4 a}$ as intermediate (supporting information, Figure S6). Hydrogenation of $\mathbf{4 a}$ was also monitored by ${ }^{1} \mathrm{H}$ NMR spectroscopy. Kinetic data could be fitted to pseudo- $1^{\text {st }}$ order decay of [4a]. The rate constant for the $\mathrm{H}_{2}$ reaction was found to be $k_{\mathrm{obs}}\left(\mathrm{H}_{2}\right)=6.28( \pm 0.06) \times 10^{-4} \mathrm{~s}^{-1}$ (Figure 2). Side-by-side kinetic runs with $\mathrm{H}_{2}$ and $\mathrm{D}_{2}$ gave a KIE of $1.02( \pm 0.01)$. 


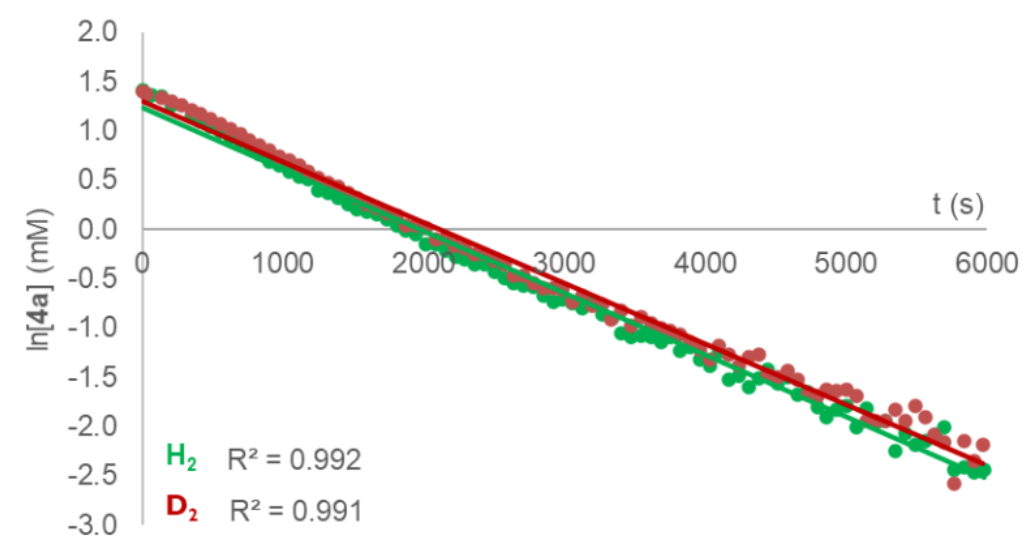

Figure 2. $\mathrm{Ln}\left[\mathbf{4 a}\right.$ ] versus time plot for reaction of $4 \mathrm{a}$ with $\mathrm{H}_{2}$ (green) and $\mathrm{D}_{2}$ (red); $[4 \mathrm{a}]_{0}=4.6 \mathrm{mM}$.

A series of plausible pathways for the hydrogenation reaction were calculated by DFT. The lowest energy pathway is depicted in Figure 3. The calculated mechanism is initiated by $\eta^{2}$-dihydrogen coordination to complex 4a to give Int-1. ${ }^{19-23}$ Formation of this intermediate occurs via an interchange mechanism $\left(\Delta \mathrm{G}^{\ddagger}{ }_{298 \mathrm{~K}}=+21.7 \mathrm{kcal} \mathrm{mol}{ }^{-1}\right)$. Oxidative addition of $\mathrm{H}_{2}$ to the $\mathrm{W}$ centre from Int-1 gives the dihydride intermediate Int-2 via a low energy barrier transition state TS-2 followed by a barrierless migration of one of the hydrides to the carbon atom of the metallocarbene to give Int-3. There is precedent for this type of 1,2-migration involving hydride and metallocarbene ligands. ${ }^{24-26}$ Prior calculations are consistent with a low energy process. ${ }^{27-29}$ Int-3 is stabilised by an agostic interaction of the newly formed $\mathrm{C}-\mathrm{H}$ bond to $W^{30}$ After two consecutive rotations steps via TS-4 and TS-5, Int-3 leads to Int-5 which is stabilised by coordination of an oxygen atom of the carbon chain. Int-5 dissociates a CO ligand through TS- 6 to give Int-6. Int-6 then rotates again through Int-7 to Int-8 which is preorganised for reductive elimination via TS-9 to afford the thermodynamically stabilised Int-9, a precursor of the final products. ${ }^{31}$ The barrier for the reductive elimination step is low $\left(\Delta \mathrm{G}^{\ddagger}{ }_{298 \mathrm{~K}}=+11.7 \mathrm{kcal} \mathrm{mol}^{-1}\right)$.

Overall, this calculated mechanism proceeds via a series of established fundamental steps of organometallic compounds namely: (i) ligand substitution (ii) oxidative addition, (iii) migratory insertion, and (iv) reductive elimination. The Gibbs activation energy corresponds to energy span from $\mathbf{4 a}$ to TS-5 $\left(\Delta \mathrm{G}^{\ddagger}{ }_{298 \mathrm{~K}}=+34.8 \mathrm{kcal} \mathrm{mol}^{-1}\right){ }^{32}$ The rate-limiting sequence involves coordination of $\mathrm{H}_{2}$, oxidative addition of $\mathrm{H}_{2}$, hydride migration from $\mathrm{W}$ to $\mathrm{C}$ and $\mathrm{CO}$ dissociation. The predicted pathway is consistent across a series of DFT functionals. 


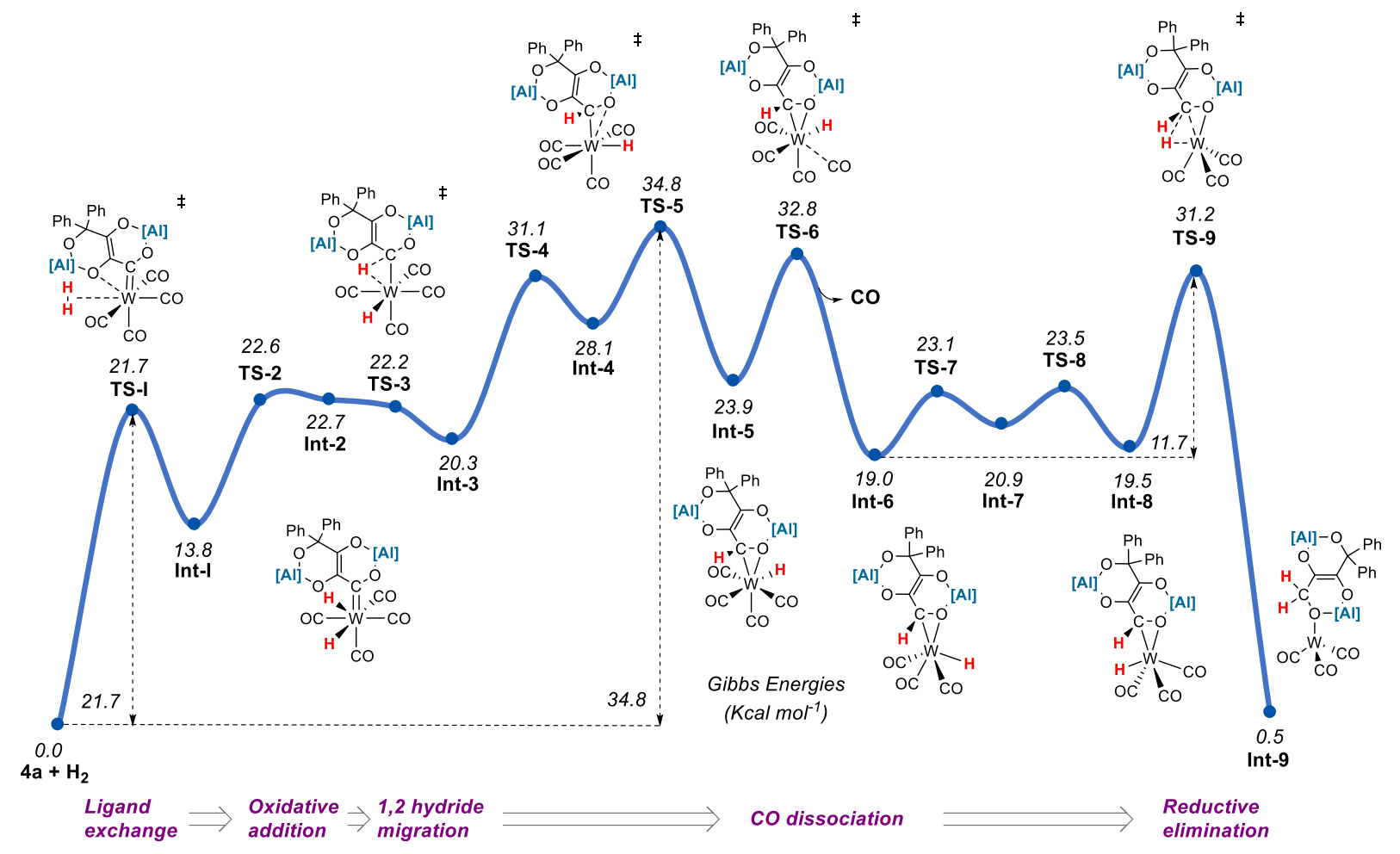

Figure 3. DFT calculated mechanism for hydrogenation of $\mathbf{4 a}$.

Consideration of the calculated reaction mechanism suggests that the assignment of a KIE in this system is complex. Although the experimentally determined KIE of $1.02( \pm 0.01)$ could be interpreted as a simple step not involving hydrogen atoms, based on the calculations it more likely arises from the combination of individual KIEs (or EIEs) from a series of steps. While oxidative addition of $\mathrm{H}_{2}$ to $\mathrm{W}$ is expected to show a normal primary $\mathrm{KIE}, \mathrm{H}_{2}$ binding often occurs with an inverse IE. ${ }^{33}$ Similarly, based on the stretching vibrational modes, hydride migration from $\mathrm{W}$ to $\mathrm{C}$ might be expected to occur with an inverse KIE. ${ }^{34}$

In summary, we report the formation of F-T type products from the combination of $\mathrm{H}_{2}, \mathrm{CO}$, organic electrophiles, and a main group reductant. The reaction scope allows the generation of both $\mathrm{C}_{3}$ and $\mathrm{C}_{4}$ chains with complete selectively. The hydrogenation step is mediated by the transition metal which likely plays a key role through activation of $\mathrm{H}_{2}$ at a site adjacent to a metallocarbene ligand. These findings greatly expand the scope and understanding of reactivity for homogeneous systems reported that combine $\mathrm{H}_{2}$ and $\mathrm{CO}$ to make hydrogenated carbon-chains. 


\section{ASSOCIATED CONTENT}

X-ray data are deposited in the Cambridge Crystallographic database: CCDC $2130349-2130351$ and 2129490-2129492. Primary data (.mnova, .txt and .xyz) are available from Imperial's Research Data Repository and available through the following link: $\underline{10.14469 / \mathrm{hpc} / 10042}$

\section{AUTHOR INFORMATION}

\section{Corresponding Author}

*m.crimmin@imperial.ac.uk

\section{Author Contributions}

The manuscript was written through contributions of all authors. All authors have given approval to the final version of the manuscript.

\section{ACKNOWLEDGMENT}

We thank Imperial College London for the award of a President's Scholarship (RYK). We also thank the EPSRC for project funding (EP/S036628/1). 


\section{REFERENCES}

(1) Schulz, H. Short History and Present Trends of Fischer-Tropsch Synthesis. Appl. Catal. A Gen. 1999, $186(1-2), 3-12$.

(2) De Klerk, A. Fischer-Tropsch Process 1. Kirk-Othmer Encyclopedia of Chemical Technology; John-Wiley and Sons, Inc.: Hoboken, NJ, 2013; pp 1-36.

(3) Anderson, R. B.; Friedel, R. A.; Storch, H. H. Fischer-Tropsch Reaction Mechanism Involving Stepwise Growth of Carbon Chain. J. Chem. Phys. 1951, 19 (3), 313-319.

(4) West, N. M.; Miller, A. J. M.; Labinger, J. A.; Bercaw, J. E. Homogeneous Syngas Conversion. Coord. Chem. Rev. 2011, 255 (7-8), 881-898.

(5) Kong, R. Y.; Crimmin, M. R. Cooperative Strategies for CO Homologation. Dalt. Trans. 2020, 49 (46), 16587-16597.

(6) B, D. Homogeneous Catalytic Hydrogenation of Carbon Monoxide: Ethylene Glycol and Ethanol from Synthesis Gas. Adv. Catal. 1983, 32 (C), 325-416.

(7) Labinger, J. A. Approaches to Homogeneously Catalyzed CO Hydrogenation: A Personal Retrospective. J. Organomet. Chem. 2017, 847, 4-12.

(8) Maitlis, P. M. Fischer-Tropsch, Organometallics, and Other Friends. J. Organomet. Chem. 2004, 689 (24 SPEC. ISS.), 4366-4374.

(9) Qi, Z.; Chen, L.; Zhang, S.; Su, J.; Somorjai, G. A. Integrating the Fields of Catalysis: Active Site Engineering in Metal Cluster, Metal Organic Framework and Metal Single Site. Top. Catal. 2020, $63(7-8), 628-634$.

(10) Demitras, G. C.; Muetterties, E. L. Metal Clusters in Catalysis. 10. A New Fischer-Tropsch Synthesis. J. Am. Chem. Soc. 1977, 99 (8), 2796-2797.

(11) Protasiewicz, J. D.; Lippard, S. J. Vanadium-Promoted Reductive Coupling of CO and Facile Hydrogenation To Form Cis-Disiloxyethylenes. J. Am. Chem. Soc. 1991, 113 (17), 6564-6570.

(12) Suess, D. L. M.; Peters, J. C. A CO-Derived Iron Dicarbyne That Releases Olefin upon Hydrogenation. J. Am. Chem. Soc. 2013, 135 (34), 12580-12583.

(13) Hu, S.; Shima, T.; Hou, Z. Hydrodeoxygenative Cyclotetramerization of Carbon Monoxide by a Trinuclear Titanium Polyhydride Complex. J. Am. Chem. Soc. 2020, 142 (47), 19889-19894.

(14) Xu, M.; Qu, Z. W.; Grimme, S.; Stephan, D. W. Lithium Dicyclohexylamide in Transition-MetalFree Fischer-Tropsch Chemistry. J. Am. Chem. Soc. 2021, 143 (2), 634-638.

(15) Kong, R. Y.; Crimmin, M. R. Carbon Chain Growth by Sequential Reactions of $\mathrm{CO}$ and $\mathrm{CO}_{2}$ with $\left[\mathrm{W}(\mathrm{CO})_{6}\right]$ and an Aluminum(I) Reductant. J. Am. Chem. Soc. 2018, 140 (42), 13614-13617.

(16) Kong, R. Y.; Batuecas, M.; Crimmin, M. R. Reactions of aluminium(I) with transition metal carbonyls: scope, mechanism and selectivity of CO homologation. Chem. Sci. 2021, 12, 1484514854.

(17) Hart, I. J.; Jeffery, J. C.; Lowry, R. M.; Stone, F. G. A. Acyl-Alkylidyne Coupling in the Synthesis 
of Dinuclear Complexes. Angew. Chem. Int. Ed. 1988, 27 (12), 1703-1705.

(18) To check if insertion could occur also into hydrogenated products, reaction of $\mathbf{3 a}$ with benzophenone was tested and no reactivity was observed, suggesting that the reaction follows the sequence insertion-hydrogenation.

(19) Although different geometries for Int-1 can be proposed, rotational barriers for $\mathrm{H}_{2}$ ligand have been calculated to be low in energy for this molecule $\left(\Delta \mathrm{G}^{\circ}{ }_{298 \mathrm{~K}}=+3.2-6.8 \mathrm{kcal} \mathrm{mol}^{-1}\right.$ and $\Delta \mathrm{G}^{\ddagger} 298 \mathrm{~K}=+0.7-$ $4.5 \mathrm{kcal} \mathrm{mol}^{-1}$ ) and are in agreement with previous results for related molecules (see supporting information).

(20) Hay, P. J. Ab Initio Theoretical Studies of Dihydrogen Coordination vs Oxidative Addition of $\mathrm{H}_{2}$ to Five-Coordinate Tungsten Complexes. J. Am. Chem. Soc. 1987, 109 (3), 705-710.

(21) Hay, P. J. Ab Initio Theoretical Studies of a Novel Tungsten Dihydrogen Complex. Chem. Phys. Lett. 1984, 103 (January), 466-469.

(22) Juergen Eckert, Gregory J. Kubas, John H. Hall, P. Jeffrey Hay, and C. M. B. Molecular Hydrogen Complexes. 6. The Barrier to Rotation of $\eta^{2}-\mathrm{H}_{2}$ in $\mathrm{M}(\mathrm{CO})_{3}\left(\mathrm{PR}_{3}\right)_{2}\left(\eta^{2}-\mathrm{H}_{2}\right) \quad(\mathrm{M}=$ Tungsten, Molybdenum; R = Cyclohexyl, Isopropyl): Inelastic Neutron Scattering, Theoretical, and Molecular Mechanics Studies. J. Am. Chem. Soc. 1990, 112, 2324-2332.

(23) Albright, T. A. Rotational Barriers and Conformations in Transition Metal Complexes. Acc. Chem. Res. 1982, 15 (5), 149-155.

(24) Osborn, V. A.; Parker, C. A.; Winter, M. J. Hydride to Carbene Migration at Molybdenum; the Isomerisation of $\mathrm{Mo}(\mathrm{H})\left\{=\mathrm{C}\left[\mathrm{CH}_{2}\right]_{3} \mathrm{NMe}\right\}(\mathrm{CO})_{2}\left(\mathrm{\eta}-\mathrm{C}_{5} \mathrm{H}_{5}\right)$ to $\mathrm{Mo}(\mathrm{CO})_{2}\left\{\eta^{2}-\mathrm{CH}\left[\mathrm{CH}{ }_{2}\right]_{3} \mathrm{NMe}\right\}\left(\eta-\mathrm{C}_{5} \mathrm{H}_{5}\right)$. J. Chem. Soc. Chem. Commun. 1986, 2 (15), 1185-1186.

(25) Charles P. Casey and Stephen M. Neumann. Reaction of Molecular Hydrogen with Transition Metal Carbene Complexes: Reductive Cleavage of the Carbene Ligand. J. Am. Chem. Soc. 1977, 99 (5), 1651-1652.

(26) Green, J. C.; Green, M. L. H.; Morley, C. P. A Kinetic Study of the 1,2-Hydrogen Shift in a Bis(nCyclopentadienyl)Tungsten System. Organometallics 1985, 4 (7), 1302-1305.

(27) Carter, E. A.; Goddard, W. A., III Methylidene Migratory Insertion into a Ruthenium-Hydrogen Bond. J. Am. Chem. Soc. 1987, 109 (2), 579- 580.

(28) Ziegler, T.; Versluis, L.; Tschinke, V. Migratory Aptitude of Hydride and Methyl toward Carbon Monoxide, Thiocarbonyl, and Carbene in $\mathrm{RMn}(\mathrm{CO})_{4} \mathrm{XY}\left(\mathrm{XY}=\mathrm{CO}, \mathrm{CS}, \mathrm{CH}_{2} ; \mathrm{R}=\mathrm{H}, \mathrm{CH}_{3}\right) . \mathrm{A}$ Theoretical Study by the Hartree-Fock-Slater Transition-State Method. J. Am. Chem. Soc. 1986, 108 (4), 612-617.

(29) Carter, E. A.; Goddard, W. A. Modeling Fischer-Tropsch Chemistry: The Thermochemistry and Insertion Kinetics of $\mathrm{CIRuH}\left(\mathrm{CH}_{2}\right)$. Organometallics 1988, 7 (3), 675-686.

(30) Alternative mechanisms in which Int-1 undergoes CO dissociation to give a pentacoordinated dihydrogen intermediate or in which $\mathrm{CO}$ dissociation and $\mathrm{H}$ migration occur simultaneously from 
Int-2 have been discarded due to their high transition state energy: TS-2a, $\Delta \mathrm{G}^{\ddagger}{ }_{298 \mathrm{~K}}=+42.3 \mathrm{kcal}$ $\mathrm{mol}^{-1}$; TS-3b, $\Delta \mathrm{G}^{\ddagger}{ }_{298 \mathrm{~K}}=+44.0 \mathrm{kcal} \mathrm{mol}^{-1}$ (see supporting information).

(31) An alternative plausible mechanism from Int-5 in which $\mathrm{CO}$ dissociation does not take place was calculated to present a similar energy $\left(\Delta \mathrm{G}^{\ddagger} 298 \mathrm{~K}=+35.9 \mathrm{kcal} \mathrm{mol}^{-1}\right)$ (see supporting information).

(32) The energy span from $4 a$ to TS-6 $\left(\Delta \mathrm{G}^{\ddagger}{ }_{298 \mathrm{~K}}=+32.8 \mathrm{Kcal} \mathrm{mol}^{-1}\right)$ is similar. These two steps are close in energy and either could be rate-limiting.

(33) Janak, K. E.; Parkin, G. Deuterium and Tritium Equilibrium Isotope Effects for Coordination and Oxidative Addition of Dihydrogen to $\left[\mathrm{W}(\mathrm{CO})_{5}\right]$ and for the Interconversion of $\mathrm{W}(\mathrm{CO})_{5}\left(\mathrm{H}_{2}-\mathrm{H}_{2}\right)$ and $\mathrm{W}(\mathrm{CO})_{5} \mathrm{H}_{2}$. Organometallics 2003, 22 (22), 4378-4380.

(34) Bullock, R. M.; Bender, B. R. Isotope Methods - Homogeneous. In Encyclopedia of Catalysis; I. Horváth, Ed.; 2000; pp 1-62.

\section{TOC graphic}

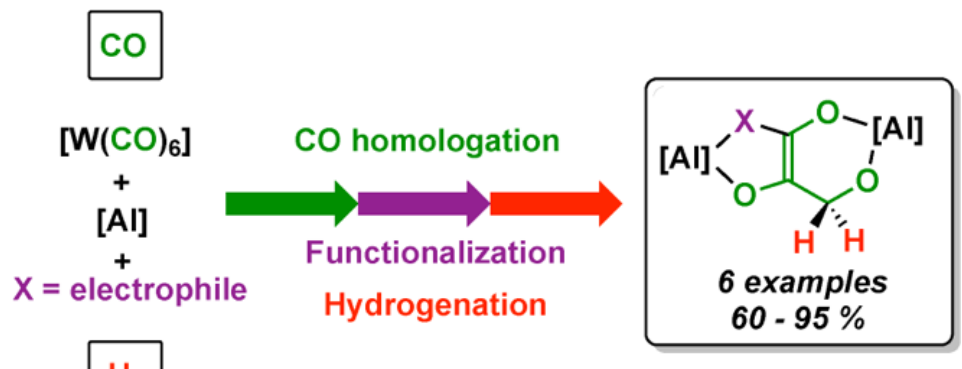

$\mathrm{H}_{2}$ 